\title{
THE RESEARCH OF THE REGENERATING ACTIVITY OF GELS BASED ON BIDENS TRIPARTITA HERB EXTRACTS ON MICE AND RATS
}

\author{
() Galkina D. A., Basevich A. V., Bolotova V. C., Podushkin V. Yu.
}

St. Petersburg State Chemical-Pharmaceutical Academy, Russia

The abundance of atopic dermatitis among children is $5-20 \%$ and among adults is $2-10 \%$. One of the advanced solutions is the development of drugs, based on phytosubstances. One of the well-known medical plants for skin treatment is Bidens tripartita (Asteraceae). It is known for its anti-inflammatory and regenerating properties. On the base of SPCPA a technology of Bidens tripartita extract obtained by $60 \%$ ethanol extraction and standardized with flavonoids was developed. The aim of this study is to examine the regenerating properties of a hydrophilic gel based on Bidens tripartita extract obtained by $60 \%$ ethanol extraction and compare them with properties of gels, based on Bidens tripartita extracts obtained by another extracting agents. Pharmacological studies were performed on 50 white outbred male mice with weigh of $18-20 \mathrm{~g}$, which were kept on a standard diet in vivarium. The mice got a medical discission of $2 \mathrm{~cm}$ long with fixed edges. The mice were devided into 5 groups according to the substance applied. The substances were: 1 - a gel, based on Bidens tripartita extract obtained by $60 \%$ ethanol extraction; 2 - a gel, based on Bidens tripar- tita extract obtained by $20 \%$ ethanol extraction; 3 - a gel, based on Bidens tripartita extract obtained by water extraction; 4 - a comparator - an ointment "Calendula"; 5 - the control group. These substances were applied on mice's discissions every day during a week until forming of scars. After that the scars were measured tensile tensiometrically. When comparing the groups of mice upon the mass of the weight at which the scar have broken, it was found out, that the heaviest weight is at the group of the gel, based on Bidens tripartita extract obtained by $60 \%$ ethanol extraction. The weight is $425 \mathrm{~g}$ and thus the scars of the first group are the toughest. The other groups were compared with the first one. The order of decreasing of scar toughness is: group 3, group 2 , group 4 , group 5 . The ratio of these groups relatively to the first group is $-23,5 \%,-33,0 \%,-34,1 \%,-38,9$ $\%$ respectively. Statistically significant differences comparing with control group were not observed. Therefore, the gel, based on Bidens tripartita extract obtained by $60 \%$ ethanol extraction has good regenerative properties and accelerates the process of scar-forming. The regenerative ability is regular and stable.

\section{INFLUENCE OF THE COMBINED PHYTODRUG ON THE NEUROTROPIC ACTIVITY OF MICE}

\section{() Galkina D. A., Chikisheva S. A., Bolotova V.Tz., Basevich A. V.}

\section{St. Petersburg State Chemical-Pharmaceutical Academy, Russia}

A dry extract of mixture containing linden leaves, clover herb and St John's wort herb (3:2:2) enriched with flavonoid fraction was developed in SPCPA. The aim of this research is studying the neurothropic activity of the phytodrug with the extract of mixture containing linden leaves (Tilia cordata folia), clover herb (Trifolium pratense herba) and St John's wort herb (Hypericum maculatum herba). Pharmacological studies were performed on 50 white outbred male mice with weigh of $18-20 \mathrm{~g}$, which were kept on a standard diet in vivarium. The assessment of neurothropic activity was performed in the open field test. The phytodrug was dosed orally with preliminary solution in water. The range of doses was from $2,2 \mathrm{mg} / \mathrm{kg}$ to $220 \mathrm{mg} / \mathrm{kg}$. The comparator agent was a phytodrug "Negrustin" at a dose of $14,6 \mathrm{mg} / \mathrm{kg}$. The mice in a control group received water. After 60 minutes of dosing, searching activity (SA), orientating activity
$(O A)$, emotional lability (EL) and agression (AG) were assessed. When comparing a group of mice, who received "Negrustin" at a dose of 14,6 mg/kg with control group, decreasing of SA, OA, EL, AG up to $74 \%, 25 \%, 25 \%$ and $33,7 \%$ respectively was observed. In groups of mice, who received doses of $0,22 \mathrm{mg} / \mathrm{kg}, 22 \mathrm{mg} / \mathrm{kg}, 220 \mathrm{mg} / \mathrm{kg}$, decreasing of OA up to $59 \%, 41 \%, 74 \%$ respectively, decrease of EL up to $50 \%, 25 \%, 0 \%$ respectively, decrease of SA up to $30 \%, 35,3 \%, 13 \%$ respectively and decrease of $A G$ up to $26 \%, 16,3 \%, 12 \%$ respectively were observed. When dosing the phytodrug at different doses, statistically significant differences comparing with control group were not observed. Maximal sedative effect was observed in group of animals, which received the phytodrug at a dose of $0,22 \mathrm{mg} / \mathrm{kg}$. The effect of the phytodrug was consistent with the effect of comparator agent "Negrustin" at a dose of $14,6 \mathrm{mg} / \mathrm{kg}$. In the com- 